\title{
CHARACTERISTICS OF THE LARVIFORM FEMALE OF THE LAMPYRID BEETLE, LAMPROPHORUS
}

\author{
By Charles T. Brues,
}

\author{
Biological Laboratories, Harvard University
}

In looking over the collection of larvæ of malacoderm beetles in the Museum of Comparative Zoology searching for specimens of the remarkable Lycidæ commonly known as "trilobite larvæ", I noted two specimens from Ceylon that represent the larva and larviform adult female of a species of Lamprophorus. The label indicates that these were received from F. Layard in January, 1865. Like the other known members of the genus the female larva attains a large size which corresponds to that of the adult female, in this case about $70 \mathrm{~mm}$.

An early reference to these larviform lampyrids is a note on page xlviii the Proceedings of the London Entomological Society for 1908 that mentions the exhibition by C. J. Gahan of specimens of Lamprophorus (Lamprigera) and Dioptoma and sets forth briefly the slight differences that distinguish the sexually mature female from the larva. In the same journal for 1912 (p. 178) Green gives a very brief description of the "grub-like" female of Dioptoma adamsi Pasc. with an account of the luminous organs which are present in both sexes. Dioptoma is now placed in the related family Rhagophthalmidæ although Lamprophorus is still retained in the Lampyridæ.

Blair $^{1}$ has described a larva, probably of Lamprophorus boyei Mots. from Sumatra. These larvæ were collected together with the male of this species at two localities. In the same paper he records the female of L. tenebrosus Walk. from Ceylon, definitely identified as it was taken in coitu with the male. He notes that it is of very similar form to the larva, "but of pale colour with more feebly chitinized in-

${ }^{1}$ Journ. Fed. Malay States Mus., vol. 8, p. 176 (1928). 
tegument; the antennæ are of similar form except that the third joint has become more elongate and divided into five small joints, the mouthparts differ in numerous particulars and the legs have a 5-jointed tarsus." In this same paper Blair gives a rather detailed description of the Sumatran larva, especially of the mouthparts and antennæ, but no further details are included concerning the more minute structures in which the female differs from the mature larva.

I have undertaken to do this for the two specimens before me as the matter is of considerable interest for it illustrates the great persistence of certain morphological characters in insects even when an almost complete degeneration of most bodily structures supervenes for one reason or another. In the great majority of cases among insects, or other animals, such great degenerative modifications or simplifications are directly traceable to parasitic life such as those shown, for example, by female Strepsiptera, parasitic earwigs and the like. Such is, of course, obviously not the case among the Lampyridæ where numerous other examples of larviform adults are well known. These occur in more than one series of related forms, at least one of which, Phengodes, is often relegated to another family and in the family Lycidæ where a closely similar condition exists in some Indomalayan genera. In the latter, as in Lamprophorous and its allies, a remarkable disparity in size between the sexes develops as the female becomes a ponderous creature in comparison with her diminutive, though normally proportioned spouse.

The fully grown larva and adult female of Lamprophorus are of essentially the same size and general proportions. The larva is not particularly extaordinary for a Lampyrid and the structure of the head with its appendages and the legs are of normal form.

The female differs most noticeably in its paler color and much more delicate integument which is far more flexible and apparently thinner. Ecdysis is complete as there is no indication of any bits or shreds of the larval cuticle still adhering to the surface of the body such as have been described by Mjöberg for one of the lycid "trilobite" larvæ which he reared to maturity. The head in dorsal view is much narrower behind than in the larva, but otherwise the dorsal segments are essentially similar in shape and even 
retain evidences of a rather complicated pattern of surface sculpture, indicating that aside from molting the pigmented layer of the cuticle, no metamorphic change in the integument takes place. The legs of the larva (Fig. 1,C) are of the usual form, with three joints and a single, simple claw. The leg of the adult female (Fig. 1,F) is a true imaginal structure with the coxa, trochanter, femur and tibia developed in more or less normal proportions and there is a five-jointed tarsus bearing two large, dentate claws.
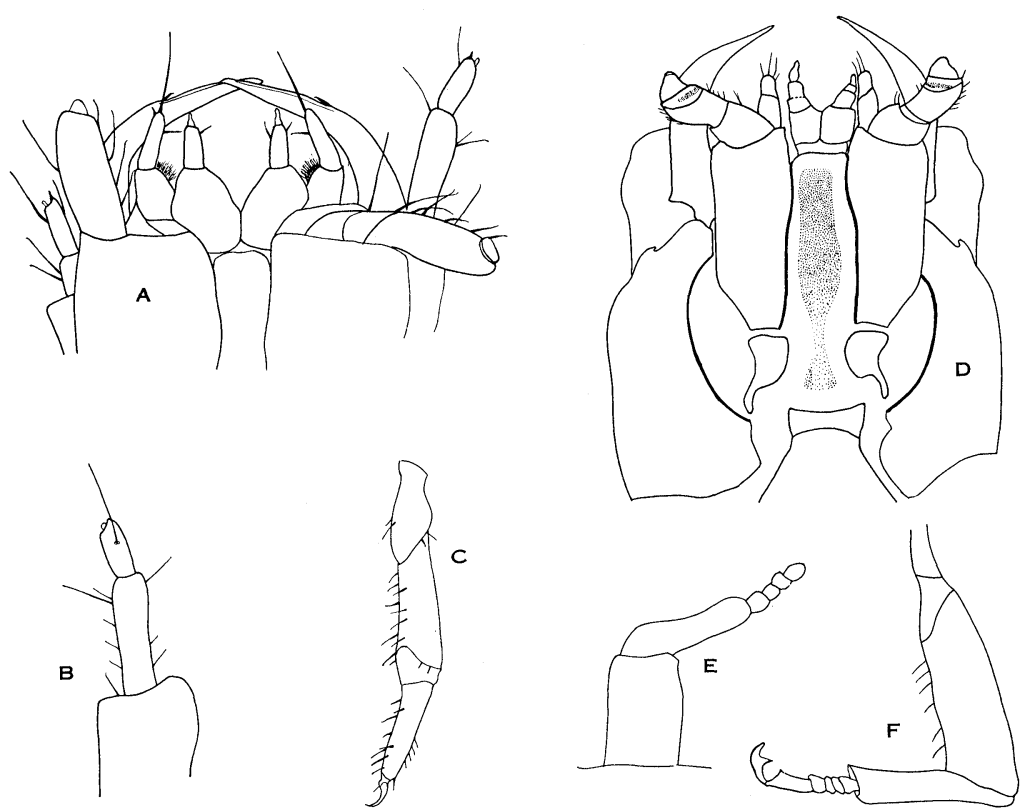

Fig. 1. Lamprophorus sp., details of larva and adult female. A, head of larva from below; B, antenna of larva; C, leg of larva; $D$, head of female from below; E, antenna of female; $F$, front leg of female.

The antennæ (Fig. 1,E) are but little longer than in the larva, but are clearly six-jointed. In this connection it is of interest to note that the males of Lamprophorus exhibit a shortening of the antennæ through the disappearance of several apical joints and shortening of the basal ones.

The presence of numerous spheroidal eggs about three 
our four millimeters in diameter proves that the specimen is fully mature.

Several changes in the mouthparts occur at the final ecdysis (Fig. 1; A, D). The large, pointed, falcate mandibles of the larva are tapered to a point and bear a conspicuous groove externally on their apical third. Those of the adult have the apex flattened into an obliquely truncate edge which lies in a vertical plane so that the tip appears acute in ventral view and only close observation indicates that the mandibles undergo a quite considerable change in shape. The maxillary palpi are obviously shortened in the adult, but the actual changes are slight. The maxillæ themselves are also shorter in the adult. The labium is changed mainly by the addition of another joint in the palpi. All of these changes in the mouthparts clearly represent a degeneration in functional capacity but they include also the retention to some slight degree of features involved in the increased complexity that normally characterizes the imaginal stage. The same is also true of the tarsi and this is of particular interest, since the segmentation of the tarsi is one of the most remarkably constant characters, among practically all groups of insects, and it is only slightly changed in the female Lamprophorus despite the inhibition of so many of the more conspicuous imaginal features and the absolutely larviform habitus.

The accompanying figures drawn for me by Mrs. A. S. O'Connor illustrate the several structures to which reference is made. 

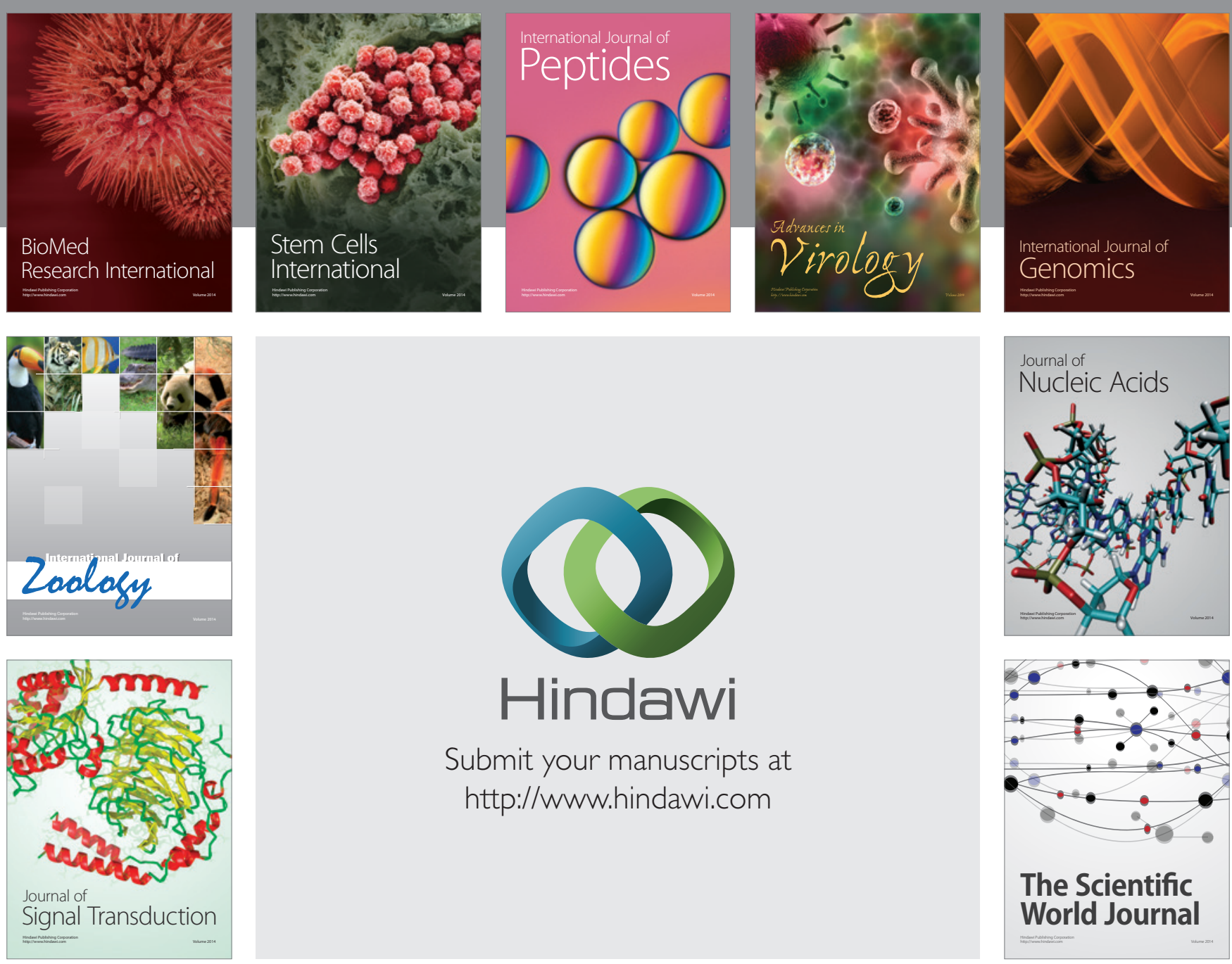

Submit your manuscripts at

http://www.hindawi.com
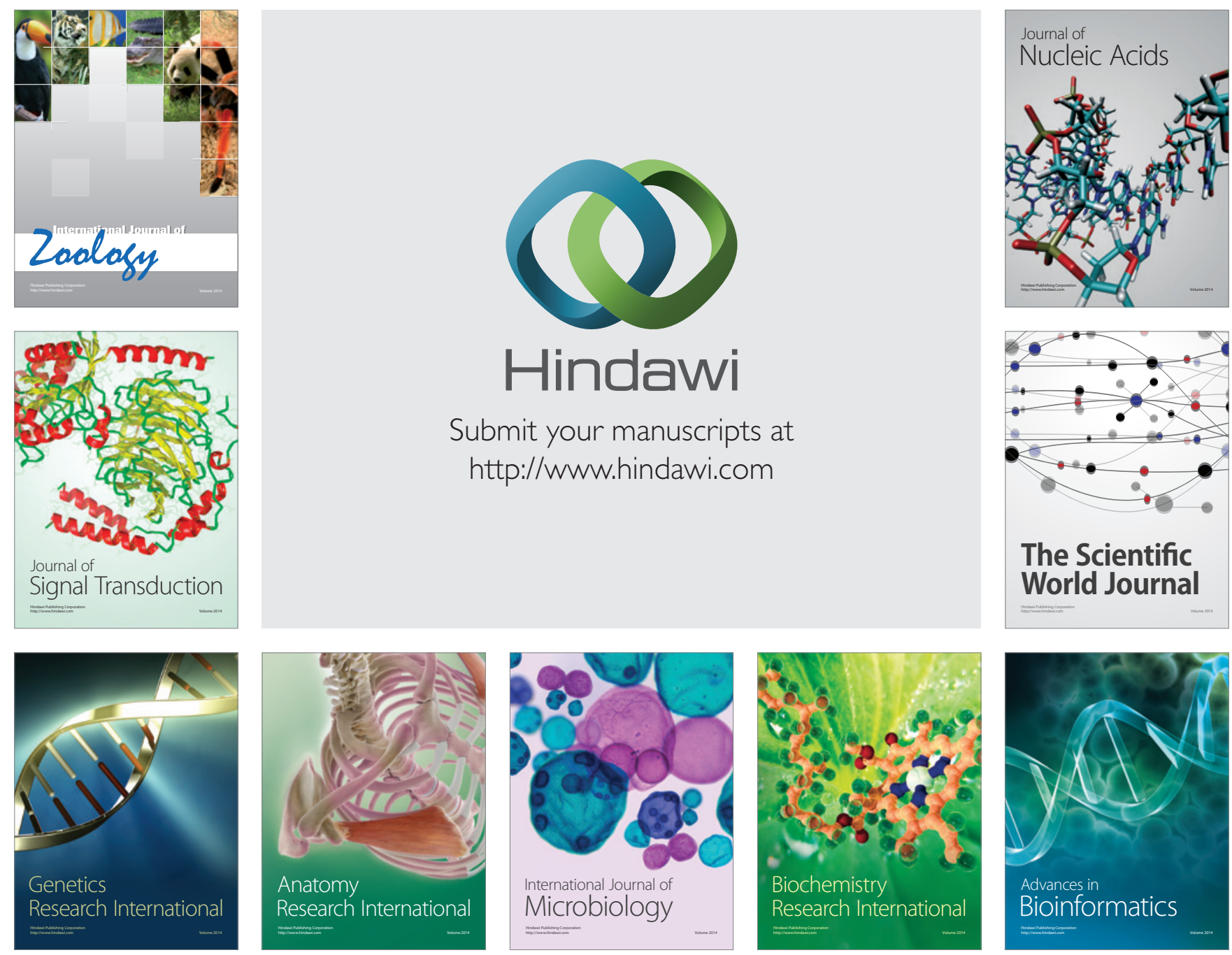

The Scientific World Journal
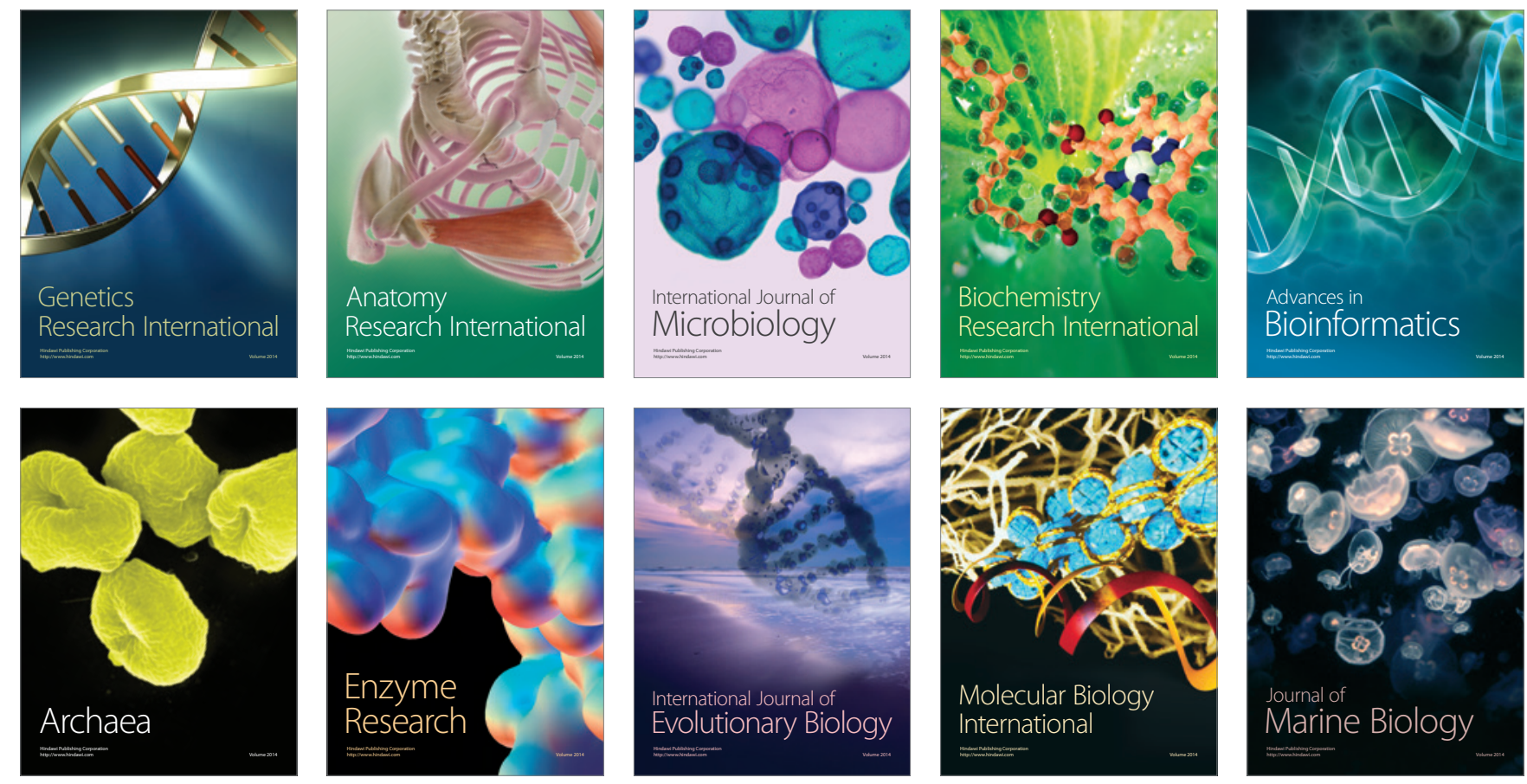